\title{
Changes in antidiabetic prescription patterns and indicators of diabetic control among 200,000 patients over 13 years at a single institution in Japan
}

\author{
Kazutoshi Fujibayashi ${ }^{*}$, Michio Hayashi ${ }^{2}$, Hirohide Yokokawa ${ }^{1}$ and Toshio Naito ${ }^{1}$
}

\begin{abstract}
Background: We examined the long-term changes in the management of diabetes at a single institution in Japan. Methods: Two repeated cross-sectional studies and a retrospective cohort study were conducted among patients who visited our institution between 2001 and 2013. We examined the changes in glycated hemoglobin (HbA1c) and glycated albumin levels, the prescription frequencies, and the daily doses of each antidiabetic agent among patients treated regularly for diabetes during the 13-year study period. The trends in control and treatment parameters were analyzed using Spearman's rank correlation coefficient.

Results: In the first repeated cross-sectional studies, 200,298 patients had their glucose metabolism indicators measured, and diabetologists prescribed medications to 193, 445 patients. Of these, 170 patients were included in the retrospective cohort study. The patients' diabetic control tended to improve over the study period. The mean $\mathrm{HbA} 1 \mathrm{c}$ level improved from 7.9 to $7.6 \%$ (from 63 to $60 \mathrm{mmol} / \mathrm{mol}$ ) ( $\mathrm{rs}=-0.11, \mathrm{p}<0.01$ ) in the cross-sectional study, corresponding to a change from 8.2 to $7.7 \%$ (from 66 to $61 \mathrm{mmol} / \mathrm{mol}$ ) ( $\mathrm{rs}=-0.22, \mathrm{p}<0.01$ ) in the retrospective study. The mean GA level improved from 22.7 to $20.7 \%$ ( $r s=-0.13, p<0.01$ ) in the cross-sectional study and from 23.5 to $21.5 \%$ $(r s=-0.14, p<0.01)$ in the retrospective study. Over the study period, prescription frequencies and daily doses of antidiabetic agents changed as treatment guidelines were altered.
\end{abstract}

Conclusions: The present study revealed a tendency toward long-term improvements in diabetic control, with changes in the prescription patterns consistent with research and guideline evidence.

Keywords: History, Drug therapy, Control, Numerical data

\section{Background}

The incidence of diabetes is rising globally. As of 2013, 382 million people had the disease, with that number expected to increase to 592 million by 2035 [1]. In Japan, $16.2 \%$ of men and $9.2 \%$ of women either have or are strongly suspected of having diabetes [2]. As the number of patients with diabetes increases, the associated medical costs rise in tandem. In 2013, global health

\footnotetext{
*Correspondence: kfujiba@juntendo.ac.jp

1 Department of General Medicine, School of Medicine, Juntendo

University, 3-1-1, Hongo, Bunkyo-ku, Tokyo 113-8421, Japan

Full list of author information is available at the end of the article
}

expenditure due to diabetes was estimated to be USD 548 billion. Moreover, those costs are expected to increase to USD 627 billion by 2035. Consequently, diabetes is considered a serious health problem worldwide [3].

Glycated hemoglobin (HbA1c) levels are affected by anemia, age, and other factors, and when used in isolation, they are not very accurate for monitoring diabetes in patients with conditions such as impaired renal function or in those who are pregnant [4-6]. Glycated albumin levels, which reflect blood glucose levels over the previous two weeks and are useful in managing diabetes with chronic renal dysfunction [7-9]. Therefore, glycated 
albumin levels are used as an indicator of diabetes management in Japan.

In 2002, intensive therapy and lowering of HbA1c were effective in preventing diabetic complications [10]. A diagnosis of metabolic syndrome that was caused by insulin resistance increases was focused on in 2005 [11]. In 2006, biguanide was designated as the first-line drug for diabetes treatment, and thiazolidine was added as the second-line drug [12]. In 2007, the importance of postprandial hyperglycemia management was shown [13]. In 2012, incretin-related drugs were added as second-line drugs [14]. In addition, a patient-centered approach was recommended.

Although the diabetes management guidelines have been updated frequently, changes in the overall treatment of diabetes and changes in the diabetes management of each patient remains unclear. Repeated cross-sectional analyses can observe overall tendencies of all patients. However, such study designs have some limitations regarding the observation of the course of each patient. In addition, retrospective cohort analyses have the opposite characteristic. Therefore, we conducted two large-scale repeated cross-sectional studies and a single long-term retrospective study to address these problems.

Our aims were to characterize the effects of evolving diabetes management guidelines by examining longterm changes in prescribing antidiabetic medications and changes in diabetic control parameters.

\section{Methods}

\section{Study population}

This article describes two repeated cross-sectional studies and a retrospective cohort study of patients who visited the Endocrinology and Metabolism Division of the Nippon Telegraph and Telephone Corporation (NTT) Medical Center, Tokyo between January 2001 and May 2013. The Endocrinology and Metabolism Division had between two and five diabetologists at a time during the study period. They treated over 10,000 outpatients and approximately 200 inpatients per year in total in an urban area around Tokyo in Japan. The analyzed information included that of inpatients and outpatients.

First, we performed two repeated cross-sectional studies to examine the changes in diabetes management parameters and prescriptions that occurred between 2001 and 2013. All patient identification (ID) numbers were coded following the data extraction so that individuals could not be identified.

\section{The repeated cross-sectional study of diabetes management parameters}

First, we extracted the blood test results for patients who had had their HbA1c or glycated albumin levels measured at the Endocrinology and Metabolism Division during the study period, together with the patients' ID numbers and test dates. The inclusion and exclusion criteria are shown in Fig. 1. The Japan Diabetes Society (JDS) HbA1c values were measured. These values were converted to International Federation of Clinical Chemistry (IFCC) values via National Glycohemoglobin Standardization Program (NGSP) values using the following formulae: HbA1c (NGSP) $(\%)=\{[$ HbA1c (JDS) $(\%) \times 1.02]+0.25(\%)\}$ and HbA1c (IFCC) $(\mathrm{mmol} /$ $\mathrm{mol})=\{[10.93 \times \mathrm{NGSP}(\%)]-23.50(\mathrm{mmol} / \mathrm{mol})\}[15$, 16]. Next, using International Statistical Classification of Diseases and Related Health Problems (ICD)-10 codes [17], we excluded patients without the following diagnoses: E10, type 1 diabetes mellitus; E11, type 2 diabetes mellitus; E12, malnutrition-related diabetes mellitus; E13, other specified diabetes mellitus; and E14, unspecified diabetes mellitus. To identify changes in diabetic control for the period from 2001 to 2013, we calculated the mean HbA1c levels, glycated albumin levels, or both per year.

\section{The repeated cross-sectional study of antidiabetic prescription frequency}

The study of antidiabetic prescription patterns was conducted similarly to the study of changes in the indicators of diabetic control. The inclusion and exclusion criteria are shown in Fig. 2. We included patients who were prescribed medication by diabetologists at the Endocrinology and Metabolism Division between January 2001 and May 2013 but excluded patients without ICD-10 codes E10 to E14. To identify trends in antidiabetic medication prescriptions, we calculated the annual prescription rate and annual median daily dose for each antidiabetic medication, based on the prescription records for the study period.

\section{The long-term retrospective cohort study of patients with diabetes}

This study was performed to assess the changes in diabetic control and prescription patterns in a group of patients who continued visiting the hospital for diabetic

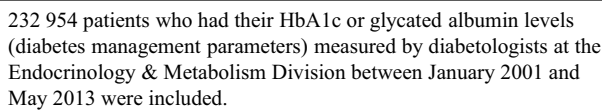

Fig. 1 Inclusion and exclusion criteria for the repeated cross-sectional study of diabetes management parameters. ICD international statistical classification of diseases and related health problems 


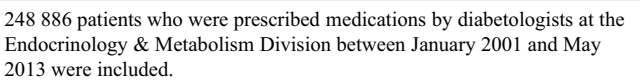

Fig. 2 Inclusion and exclusion criteria for the repeated cross-sectional study of antidiabetic prescriptions. ICD international statistical classification of diseases and related health problems

management from 2001 to 2013. The inclusion and exclusion criteria are shown in Fig. 3. First, we defined patients who had their HbA1c levels measured at least four times a year and at least twice in 2013 as "visiting patients with diabetes." In general, during diabetes treatment in Japan, HbA1c measurements are obtained once every one to three months, meaning that almost all patients who had their HbA1c levels measured at least four times a year could be considered to have diabetes requiring treatment. From among the visiting patients with diabetes, we then extracted all patients who attended hospital for treatment of their diabetes during the 13 years from 2001 to 2013. We calculated the mean values of each management parameter for each year in each patient who continued to visit the hospital.

We extracted patients, from the repeated cross-sectional study of antidiabetic prescriptions, whose ID numbers matched those of the visiting patients with diabetes.
We then determined which antidiabetic medications were prescribed to these patients each year, then calculated the median daily dose of each antidiabetic medication per year per visiting patient. Finally, using the patient ID numbers, we combined the annual means for the diabetic control parameters, the antidiabetic medication prescription rates, and the annual median daily doses of antidiabetic medications. From this combined dataset, we estimated the trends in diabetic control parameters (based on the means per year), the annual prescription frequency per antidiabetic medication (based on the means per year), and the daily doses of antidiabetic medications (based on the medians per year) in patients who continued receiving treatment for diabetes between 2001 and 2013.

\section{Statistical analysis}

In the repeated cross-sectional studies, trends for changes in diabetic control parameters and the changes in daily doses of antidiabetic medications were estimated using Spearman's rank correlation coefficient. For the control parameters, negative correlation coefficients were interpreted as being indicative of improvements in diabetic control; for the medication usage, positive correlation coefficients were considered to indicate an increase in the daily dose of an antidiabetic medication. Based on the data regarding the patients' HbA1c and glycated albumin values, participants were divided into four HbA1c categories: $<6 \%(<42 \mathrm{mmol} / \mathrm{mol}), 6$ to $<7 \%$ ( 42 to $<53 \mathrm{mmol} / \mathrm{mol}$ ), 7 to $<8 \%$ (53 to $<64 \mathrm{mmol} / \mathrm{mol}$ ), and $\geq 8 \%(\geq 64 \mathrm{mmol} / \mathrm{mol}$ ) (derived from the Japanese

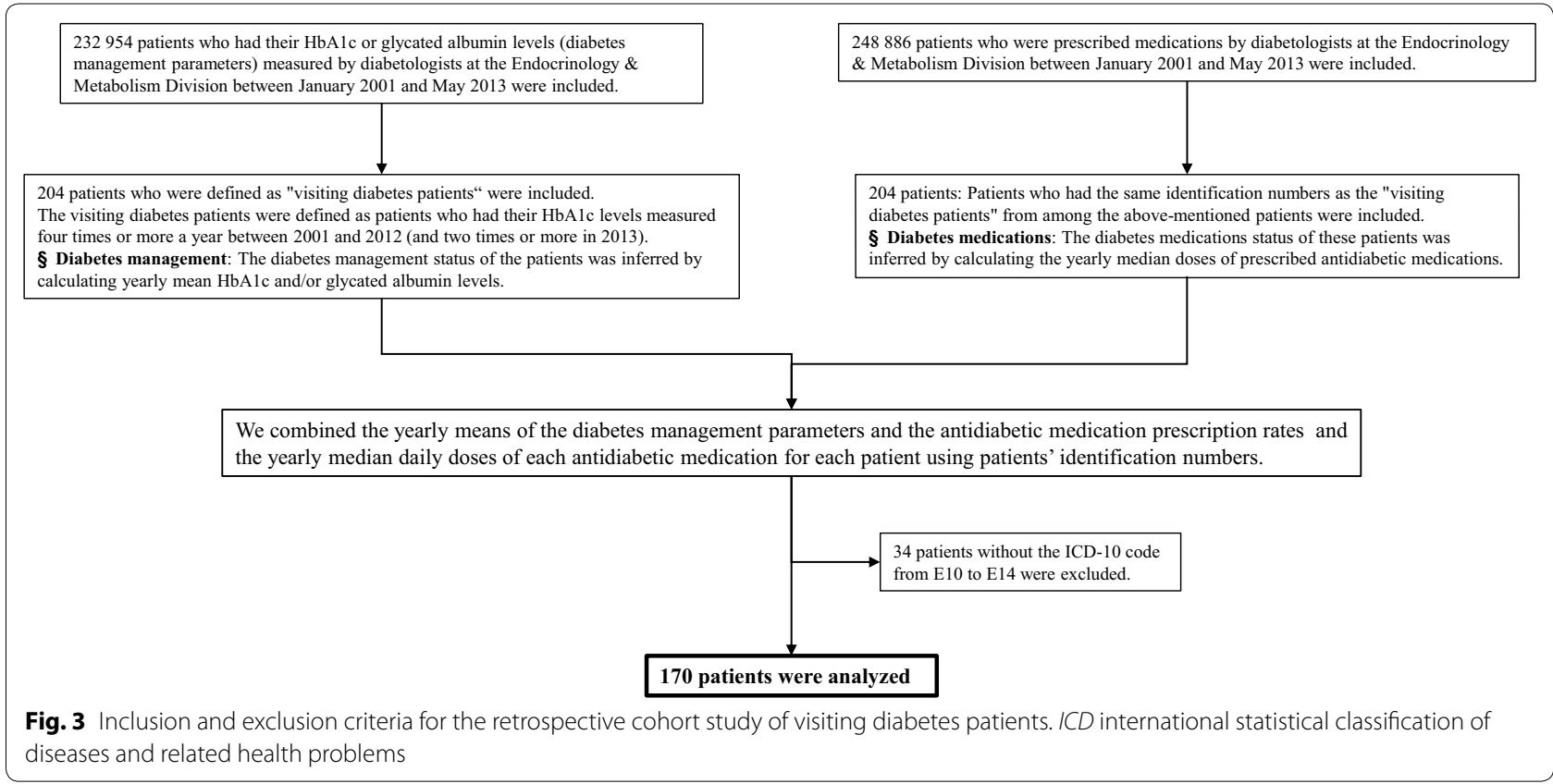


guidelines) and equivalent glycoalbumin quartiles [18]. The annual changes in each category were evaluated using the Chi square test. Subsequently, trends in the prescription frequencies of antidiabetic medications were analyzed using the Cochran-Armitage test for trend. Annual changes in the mean diabetic control parameters, the median daily antidiabetic medication doses, and the mean antidiabetic medication prescription frequencies were evaluated in the retrospective cohort study using the same methods as for the cross-sectional studies. However, although HbA1c categories were created in the same way, glycated albumin quartiles were based on the mean glycated albumin levels of the retrospective cohort. All calculations were performed with the statistical software JMP Pro version 11 (SAS Institute Inc., Cary, NC, USA). Continuous data are reported as mean \pm standard deviation or as median values (inter-quartile range) [range]. $\mathrm{p}<0.05$ were considered statistically significant.

\section{Results}

The repeated cross-sectional study of diabetic control

Table 1 shows extracted glycated hemoglobin and extracted glycated albumin data for changes in the parameters of diabetic control observed in the repeated cross-sectional study. An additional file shows this in detail (see Additional file 1). A total of 200,298 patients were included, of whom approximately $70 \%$ were men. The HbA1c levels of 199,276 patients were measured between 2001 and 2013, and the glycated albumin levels of 160,191 were measured between 2003 and 2013 . The mean HbA1c level tended to decrease from $7.8 \%$ $(62 \mathrm{mmol} / \mathrm{mol})$ in 2001 to $7.5 \%(58 \mathrm{mmol} / \mathrm{mol})$ in 2013 ( $\mathrm{rs}=-0.11, \mathrm{p}<0.01)$. Regarding the four HbA1c categories, the proportion of patients with HbA1c levels $>8 \%$ (>64 $\mathrm{mmol} / \mathrm{mol}$ ) decreased from $43 \%$ in 2001 to $30 \%$ in 2013, while the proportion of patients with HbA1c levels of 6 to $<7 \%$ ( 42 to $<53 \mathrm{mmol} / \mathrm{mol}$ ) increased from $19 \%$ in 2001 to $30 \%$ in 2013. Similar to the results for HbA1c, the mean glycated albumin level tended to decrease from $22.7 \%$ in 2003 to $20.7 \%$ in 2013 ( $\mathrm{rs}=-0.13, \mathrm{p}<0.01$ ). Furthermore, the proportion of patients with glycated albumin levels $\geq 20.7 \%$ decreased from $62 \%$ in 2003 to $43 \%$ in 2013, while the proportion of patients with glycated albumin levels $<18.0 \%$ increased from $15 \%$ in 2003 to $35 \%$ in 2013.

\section{The repeated cross-sectional study of antidiabetic prescription frequency}

Table 2 shows extracted antidiabetic medication prescription data for changes in the prescription frequencies and daily doses of antidiabetic medications. An additional file shows this in detail (see Additional file 2). In total, 248,886 prescriptions were identified, for which data on 816,666 medications and treatments were identified, but we were not able to analyze 575 prescriptions (0.07\%). After exclusion, data for 193,445 patients were analyzed. For biguanides, both the prescription frequency (21\% in 2001 and $34 \%$ in 2013) and the daily dose (metformin $\mathrm{rs}=0.36$ ) increased. Notably, the prescription frequency of dipeptidyl peptidase- 4 inhibitors increased significantly from $2 \%$ in 2010 to $38 \%$ in 2013 , as did the daily dose (sitagliptin $r s=0.10$; alogliptin $r s=0.14$; and vildagliptin $\mathrm{rs}=0.19$ ). The daily dose of $\alpha$-glucosidase inhibitors also increased (voglibose $\mathrm{rs}=0.30$ and acarbose rs $=0.04$ ). By contrast, for sulfonylureas, both the prescription frequency (34\% in 2001 to $29 \%$ in 2013) and daily dose of (glimepiride rs $=-0.38$ ) decreased significantly. In addition, the daily doses of meglitinides decreased slightly (nateglinide $r s=-0.04$ and mitiglinide $\mathrm{rs}=-0.12$ ). More recently, the prescription frequency of thiazolidine decreased from 2011 onwards.

The retrospective cohort study of visiting diabetes patients In the retrospective study, we analyzed the data for 170 patients who continued to visit our hospital for diabetes treatment throughout the 13-year study period. We included patients for whom annual information was available about both diabetic control parameters and antidiabetic medication usage.

Table 3 shows extracted glycated hemoglobin and extracted glycated albumin data for annual changes in the mean values for diabetic control. An additional file shows this in detail (see Additional file 3). Similar to the results of the repeated cross-sectional studies, the mean values tended to decrease (HbA1c rs $=-0.22, \mathrm{p}<0.01$; glycated albumin rs $=-0.14, \mathrm{p}<0.01)$. As for the four HbA1c categories, the proportion of patients with HbA1c levels $>8 \%$ ( $>64 \mathrm{mmol} / \mathrm{mol}$ ) decreased from $62 \%$ in 2001 to $31 \%$ in 2013, while the proportion of patients with $\mathrm{HbA1c}$ levels of 6 to $<7 \%$ ( 42 to $<53 \mathrm{mmol} / \mathrm{mol}$ ) increased from $8 \%$ in 2001 to $27 \%$ in 2013 . In addition, the proportion of patients with glycated albumin levels $\geq 22.0 \%$ fell from $66 \%$ in 2003 to $37 \%$ in 2013, and the proportion of patients with glycated albumin levels $<22.0 \%$ increased from $35 \%$ in 2003 to $63 \%$ in 2013.

Table 4 shows extracted antidiabetic medication prescription data for the prescription frequencies and median daily doses, calculated annually, of the antidiabetic medications identified in the retrospective cohort. An additional file shows this in detail (see Additional file 4). The prescription frequency of dipeptidyl peptidase- 4 inhibitors increased from $1 \%$ in 2010 to $41 \%$ in 2013. The median daily doses of $\alpha$-glucosidase inhibitors and biguanides increased per year during the study period (voglibose $r s=0.26$; metformin $r s=0.28$ ). As for sulfonylureas, the median daily dose (glimepiride 
Table 1 The extracted glycated hemoglobin and extracted glycated albumin data in the first repeated cross-sectional study

\begin{tabular}{|c|c|c|c|c|c|c|}
\hline Year & 2001 & 2005 & 2010 & 2013 & $r s^{*}$ & p value* \\
\hline Measured $\mathrm{HbA1c}(\mathrm{n})$ & 10,651 & 14,342 & 18,783 & 7846 & & \\
\hline HbA1c (NGSP) (\%) & $7.9 \pm 1.4$ & $7.9 \pm 1.4$ & $7.7 \pm 1.4$ & $7.6 \pm 1.4$ & -0.11 & $<0.01$ \\
\hline $\mathrm{HbA1c}(\mathrm{IFCC})(\mathrm{mmol} / \mathrm{mol})$ & $63 \pm 16$ & $63 \pm 16$ & $60 \pm 15$ & $59 \pm 15$ & & \\
\hline \multicolumn{7}{|l|}{$\mathrm{HbA1c}(\mathrm{NGSP})$ group $^{\mathrm{a}}$} \\
\hline$<6 \%(\%)$ & $615(6)$ & $471(3)$ & $935(5)$ & $511(7)$ & & \\
\hline$\geq 6 \%$ and $<7 \%(\%)$ & $1997(19)$ & $2786(19)$ & $5194(28)$ & $2367(30)$ & & \\
\hline$\geq 7 \%$ and $<8 \%(\%)$ & $3457(33)$ & $5238(37)$ & $6621(35)$ & $2585(33)$ & & \\
\hline$\geq 8 \%(\%)$ & $4582(43)$ & $5847(41)$ & $6033(32)$ & $2383(30)$ & & $<0.01^{\#}$ \\
\hline Year & 2003 & 2005 & 2010 & 2013 & $\mathrm{rs}^{*}$ & p value* \\
\hline Measured glycated albumin (n) & 8415 & 12,934 & 17,681 & 7463 & & \\
\hline Glycated albumin (\%) & $22.7 \pm 5.3$ & $22.5 \pm 5.6$ & $21.2 \pm 5.5$ & $20.7 \pm 5.7$ & -0.13 & $<0.01$ \\
\hline \multicolumn{7}{|l|}{ Glycated albumin quartile ${ }^{a}$} \\
\hline$<18 \%(\%)$ & $1281(15)$ & $2348(18)$ & $5173(29)$ & $2584(35)$ & & \\
\hline$\geq 18 \%$ and $<20.7 \%(\%)$ & $1919(23)$ & $3004(23)$ & $4501(26)$ & $1728(23)$ & & \\
\hline$\geq 20.7 \%$ and $<24.2 \%(\%)$ & $2487(30)$ & $3737(29)$ & $4048(23)$ & $1622(22)$ & & \\
\hline$\geq 24.2 \%(\%)$ & $2728(32)$ & $3845(30)$ & $3959(22)$ & $1528(21)$ & & $<0.01^{\#}$ \\
\hline
\end{tabular}

Mean \pm standard deviation or $\mathrm{n}(\%)$

NGSP National Glygohemoglobin Standardization Program, IFCCThe International Federation of Clinical Chemistry and Laboratory Medicine

* Analysis results over 13 years; Additional file 1 shows this in detail

\# Using the Chi square test

a Percentages in this column may not add up to exactly $100 \%$ because of rounding up

Table 2 The extracted antidiabetic medication prescription data obtained in the second repeated cross-sectional study

\begin{tabular}{|c|c|c|c|c|c|c|}
\hline Year & 2001 & 2005 & 2010 & 2013 & $\mathrm{rs}^{\#}$ & p value ${ }^{\#}$ \\
\hline$n$ & 14,996 & 13,976 & 17,561 & 3118 & & \\
\hline Sulfonylureas (\%) & $5102(34)$ & $4016(29)$ & $5142(29)$ & $896(29)$ & & $<0.01^{*}$ \\
\hline Glimepiride (n) & 197 & 2414 & 4399 & 783 & & \\
\hline Glimepiride (mg) & $3(2,4)[0.5,6]$ & $2(1,3)[0.5,6]$ & $1(0.5,2)[0.5,6]$ & $1(0.5,1.5)[0.5,6]$ & -0.38 & $<0.01$ \\
\hline Biguanide (\%) & $3194(21)$ & $3633(26)$ & $5432(31)$ & $1050(34)$ & & $<0.01^{*}$ \\
\hline Metformin (n) & 3164 & 3622 & 5430 & 1050 & & \\
\hline Metformin (mg) & $750(750,750)[250,1000]$ & $750(750,750)[250,1000]$ & $750(750,750)[250,1500]$ & $750(750,1500)[250,2250]$ & 0.36 & $<0.01$ \\
\hline Thiazolidine (\%) & $338(2)$ & $1907(14)$ & $6983(40)$ & $758(24)$ & & $<0.01^{*}$ \\
\hline Pioglitazone (mg) & $30(30,30)[15,60]$ & $15(15,30)[7.5,30]$ & $15(15,30)[7.5,45]$ & $15(15,30)[7.5,45]$ & 0.01 & 0.01 \\
\hline$a-G l(\%)$ & $2936(20)$ & $2696(19)$ & $3966(23)$ & $561(18)$ & & $<0.01^{*}$ \\
\hline Voglibose (n) & 2351 & 2394 & 3390 & 493 & & \\
\hline Voglibose (mg) & $0.6(0.6,0.9)[0.2,0.9]$ & $0.6(0.6,0.9)[0.2,0.9]$ & $0.9(0.6,0.9)[0.2,0.9]$ & $0.9(0.6,0.9)[0.3,0.9]$ & 0.30 & $<0.01$ \\
\hline Meglitinides (\%) & $654(4)$ & $1352(10)$ & $1418(8)$ & $155(5)$ & & $0.45^{*}$ \\
\hline Nateglinide (n) & 654 & 1275 & 1170 & 127 & & \\
\hline Nateglinide (mg) & $270(270,270)[60,360]$ & $270(180,270)[30,360]$ & $270(180,270)[30,360]$ & $270(120,270)[60,360]$ & -0.04 & $<0.01$ \\
\hline DPP4I (\%) & $0(0)$ & $0(0)$ & $361(2)$ & $1176(38)$ & & $<0.01^{*}$ \\
\hline Sitagliptin (n) & 0 & 0 & 361 & 818 & & \\
\hline Sitagliptin (mg) & & & $50(50,50)[25,100]$ & $50(25,50)[25,100]$ & 0.10 & $<0.01$ \\
\hline Insulins (\%) & $3550(24)$ & $5085(36)$ & $5660(32)$ & $990(32)$ & & $<0.01^{*}$ \\
\hline
\end{tabular}

Median (interquartile range) [range] or $\mathrm{n}(\%)$

a-Gl a-glucosidase inhibitors, DPP4/ dipeptidyl peptidase-4 inhibitors

\# Analysis results over 13 years; Additional file 2 shows this in detail

* According to the Cochran-Armitage trend test 
Table 3 The extracted glycated hemoglobin and extracted glycated albumin data obtained in the retrospective cohort study

\begin{tabular}{|c|c|c|c|c|c|c|}
\hline Year & 2001 & 2005 & 2010 & 2013 & $\mathrm{rs}^{*}$ & p value* \\
\hline Evaluated HbA1c (NGSP) (n) & 170 & 170 & 170 & 170 & & \\
\hline $\mathrm{HbA1c}(\mathrm{NGSP})^{\mathrm{a}}(\%)$ & $8.2 \pm 0.9$ & $8.0 \pm 0.9$ & $7.9 \pm 1.0$ & $7.7 \pm 1.1$ & -0.22 & $<0.01$ \\
\hline $\mathrm{HbA} 1 \mathrm{c}(\mathrm{IFCC})^{\mathrm{a}}(\mathrm{mmol} / \mathrm{mol})$ & $67 \pm 10$ & $64 \pm 9$ & $63 \pm 11$ & $60 \pm 12$ & & \\
\hline \multicolumn{7}{|l|}{ HbA1c (NGSP) group b } \\
\hline$<6 \%(\%)$ & $0(0.0)$ & $0(0.0)$ & $1(1)$ & $1(1)$ & & \\
\hline$\geq 6 \%$ and $<7 \%(\%)$ & $14(8)$ & $15(9)$ & $21(12)$ & $45(27)$ & & \\
\hline$\geq 7 \%$ and $<8 \%(\%)$ & $51(30)$ & $73(43)$ & $79(47)$ & $72(42)$ & & \\
\hline$\geq 8 \%(\%)$ & $105(62)$ & $82(48)$ & $69(41)$ & $52(31)$ & & $<0.01^{\#}$ \\
\hline Year & 2003 & 2005 & 2010 & 2013 & $\mathrm{rs}^{*}$ & $p$ value* \\
\hline Evaluated glycated albumin (n) & 136 & 170 & 170 & 168 & & \\
\hline Glycated albumin ${ }^{\mathrm{a}}(\%)$ & $23.5 \pm 3.6$ & $22.8 \pm 3.5$ & $22.3 \pm 3.9$ & $21.5 \pm 4.4$ & -0.14 & $<0.01$ \\
\hline \multicolumn{7}{|l|}{ Glycated albumin quartile $^{b}$} \\
\hline$<19.7 \%(\%)$ & $20(15)$ & $28(17)$ & $45(27)$ & $59(35)$ & & \\
\hline$\geq 19.7 \%$ and $<22.0 \%(\%)$ & $27(20)$ & $52(31)$ & $45(27)$ & $47(28)$ & & \\
\hline$\geq 22.0 \%$ and $<24.6 \%(\%)$ & $42(31)$ & $40(24)$ & $43(25)$ & $26(16)$ & & \\
\hline$\geq 24.6 \%(\%)$ & $47(35)$ & $50(29)$ & $37(22)$ & $36(21)$ & & $<0.01^{\#}$ \\
\hline
\end{tabular}

Mean \pm standard deviation or $\mathrm{n}(\%)$

NGSP national glygohemoglobin standardization program; IFCC the international federation of clinical chemistry and laboratory medicine

* Analysis results over 13 years; Additional file 3 shows this in detail

\# Using the Chi square test

a Yearly mean value for each patient

b Percentages in this column may not add up to exactly $100 \%$ because of rounding up

rs $=-0.45)$ and mean prescription rate $(46 \%$ in 2001 and $35 \%$ in 2013) both decreased annually. The yearly median daily dose of meglitinides also decreased (nateglinide rs $=-0.18$ ), and the prescription frequency of thiazolidine decreased from 2012 onwards.

\section{Discussion}

In the present study, we conducted two large-scale repeated cross-sectional studies and a long-term retrospective cohort study to examine the long-term changes in prescribing antidiabetic medications and to examine the associated changes in diabetic control. First, we demonstrated, through changes in parameters of glycemic control, that diabetes management improved over the study period. In addition, we showed the characteristics of changes in antidiabetic prescribing at our institution over a 10-year period. To the best of our knowledge, this is the first large-scale, long-term observational study of diabetes based on electronic medical records in Japanese patients.

We obtained evidence that parameters of longterm diabetic control improved, consistent with the results of a previous multicenter prospective study by the Japan Diabetes Clinical Data Management Study Group (JDDM), which revealed a tendency toward improved HbA1c levels [19]. In 2014, the JDDM had
98 participating institutions in Japan and had approximately 74,000 registered patients with diabetes. However, other long-term interventional studies have failed to detect any tendency toward improvement in $\mathrm{HbA1c}$ levels [20-23]. Similar to the repeated cross-sectional studies carried out here, the JDDM study was also a repeated cross-sectional study. However, such crosssectional studies are limited in their ability to estimate the long-term management statuses of individual patients, while the intervention studies were limited to the available methods for treating eligible patients and had HbAlc targets set in advance. Accordingly, the results of these studies cannot readily be applied to clinical practice.

The present research included a retrospective cohort study to assess changes in patients over the 13-year study period. In addition, we included glycated albumin levels. By examining glycated albumin levels, our assessment of changes in management was also based on two parameters. Therefore, the present results provide more useful estimates of the long-term trends in clinical diabetes management.

The present study showed that there were large changes in the prescription of antidiabetic medications over the 13-year study period. Changes in diabetes management guidelines and several factors may 
Table 4 The extracted antidiabetic medication prescription data obtained in the retrospective cohort study

\begin{tabular}{|c|c|c|c|c|c|c|}
\hline Year & 2001 & 2005 & 2010 & 2013 & $\mathrm{rs}^{\#}$ & p value ${ }^{\#}$ \\
\hline$n$ & 170 & 170 & 170 & 170 & & \\
\hline Sulfonylureas (\%) & $78(46)$ & $63(37)$ & $67(39)$ & $59(35)$ & & $0.02^{*}$ \\
\hline Glimepiride (n) & 12 & 31 & 54 & 47 & & \\
\hline Glimepiride $^{\mathrm{a}}(\mathrm{mg})$ & $3(2,5.625)[1,6]$ & $3(2,4)[1,6]$ & $1.875(1,3)[0.5,6]$ & $1(0.5,2)[0.5,6]$ & -0.45 & $<0.01$ \\
\hline Biguanide (\%) & $78(46)$ & $83(49)$ & $84(49)$ & $76(45)$ & & $0.76^{*}$ \\
\hline Metformin (n) & 77 & 83 & 84 & 76 & & \\
\hline Metformin ${ }^{\mathrm{a}}(\mathrm{mg})$ & $750(750,750)[375,750]$ & $750(750,750)[250,750]$ & $750(750,750)[250,1000]$ & $750(750,1500)[250,2250]$ & 0.28 & $<0.01$ \\
\hline Thiazolidine (\%) & $5(3)$ & $35(21)$ & $83(49)$ & $48(28)$ & & $<0.01^{*}$ \\
\hline Pioglitazone ${ }^{\mathrm{a}}(\mathrm{mg})$ & $30(30,30)[30]$ & $15(15,30)[7.5,30]$ & $15(15,30)[7.5,45]$ & $15(15,30)[7.5,45]$ & 0.06 & 0.16 \\
\hline$a-G l(\%)$ & $54(32)$ & $56(33)$ & $60(35)$ & $43(25)$ & & $0.30^{*}$ \\
\hline Voglibose (n) & 43 & 50 & 52 & 37 & & \\
\hline Voglibose $^{\mathrm{a}}(\mathrm{mg})$ & $0.9(0.6,0.9)[0.4,0.9]$ & $0.6(0.6,0.9)[0.2,0.9]$ & $0.9(0.6,0.9)[0.2,0.9]$ & $0.9(0.6,0.9)[0.3,0.9]$ & 0.26 & $<0.01$ \\
\hline Meglitinides (\%) & $12(7)$ & $15(9)$ & $22(13)$ & $8(5)$ & & $0.44^{*}$ \\
\hline Nateglinide (n) & 12 & 15 & 19 & 6 & & \\
\hline Nateglinide $^{\mathrm{a}}(\mathrm{mg})$ & $270(270,270)[270,270]$ & $270(270,270)[60,270]$ & $270(180,270)[60,360]$ & $135(90,225)[90,360]$ & -0.18 & 0.01 \\
\hline DPP4I (\%) & $0(0)$ & $0(0)$ & $1(1)$ & $70(41)$ & & $<0.01^{*}$ \\
\hline Sitagliptin (n) & 0 & 0 & 1 & 52 & & \\
\hline Sitagliptin $^{\mathrm{a}}(\mathrm{mg})$ & & & $50(50,50)[50,50]$ & $50(25,50)[25,100]$ & 0.09 & 0.30 \\
\hline Insulins (\%) & $69(41)$ & $96(57)$ & $97(57)$ & $93(55)$ & & $<0.01^{*}$ \\
\hline
\end{tabular}

Median (interquartile range) [range] or $\mathrm{n}(\%)$

a-Gl a-glucosidase inhibitors, DPP4I dipeptidyl peptidase-4 inhibitors

\# Analysis results over 13 years; Additional file 4 shows this in detail

* According to the Cochran-Armitage trend test

a Yearly median daily dose for each patient

explain the changes seen in prescription patterns during the study period. First, in the mid-2000s, metabolic syndrome and the recommendation of the guidelines seemed to promote prescriptions of thiazolidine and $\alpha$-glucosidase inhibitors and increase the daily dose of voglibose [11-13]. Second, the daily dose of glimepiride and meglitinides showed a tendency to decrease around 2010. Previous studies have shown that severe hypoglycemia is associated with health risks during the treatment of diabetes [24-26]. It is therefore recommended that during pharmaceutical treatment for diabetes, treatment strategies should be employed to avoid unnecessary hypoglycemia [14, 27]. One study on antidiabetic medication prescription rates in the USA showed trends toward increases in the prescription rates of biguanides and dipeptidyl peptidase- 4 inhibitors, with a concurrent trend toward reductions in the prescription rates of sulfonylureas [28], consistent with the findings of the present study. Monotherapy with biguanides or dipeptidyl peptidase- 4 inhibitors is associated with a lower risk of inducing hypoglycemia than sulfonylurea treatment. Attempts to reduce the risk of hypoglycemia may account for similar trends in prescription rates in Japan and the USA. After 2010, the prescription rates of dipeptidyl peptidase-4 inhibitors increased, and the daily doses of metformin increased. On the other hand, the prescription rates of thiazolidine decreased. Dipeptidyl peptidase- 4 inhibitors were introduced clinically in Japan in 2009, while the maximum insurance-covered dose of metformin was increased from 750 to $2250 \mathrm{mg} /$ day in 2010. Recent studies have also suggested that thiazolidine increases the risk of bladder cancer and has negative effects on bones [29,30]. In 2012, dipeptidyl peptidase- 4 inhibitors were added to the second line of diabetes treatment [14]. Changes in guidelines and these factors may explain several observed trends after 2010. Although the tendency to increase the prescription rates was shown in the repeated cross-sectional study, we were interested in the lower prescription rates of biguanide. We thought that this issue was due to Japanese guidelines and a characteristic of Japanese patients with diabetes. Since the 2000s, Japanese diabetes treatment guidelines recommend that physicians provide care in accord with an individual patient's status. These guidelines do not designate the first-line drug of diabetes pharmacotherapy [18]. In addition, as is widely known, it is thought that one of the major cause of Japanese 
diabetes is a deficiency of insulin secretion. These factors may explain the low prescription rates of biguanide.

Our study had several limitations. First, we could not confirm whether participants had firm diagnoses of diabetes and visited only our institution for treatment over the 13 years of this study. We defined patients as having diabetes if they visited the Endocrinology and Metabolism Division, had a recorded diagnosis of E10 to E14 according to the ICD-10, and had their HbA1c levels measured. However, because this was a retrospective study based on medical records, we do not know if these patients actually met the diagnostic criteria for diabetes. In addition, not all patients who had their HbA1c levels measured may have attended our institution regularly for diabetes management. However, the measurement of HbA1c is not approved in Japan for individuals without diabetes or where there is no clinical suspicion of diabetes. Similarly, the prescription of antidiabetic medications has not been approved for patients without diabetes. Therefore, we are confident that almost all of the participants in our analysis had diabetes.

Second, the causal relationships between changes in the use of antidiabetic medications and variations in the parameters of diabetic control remain unclear. Indeed, this was only an observational study, so we cannot infer which treatments improved diabetic control. We also did not investigate insulin prescriptions in detail. Therefore, further prospective studies are needed to analyze which factors help improve diabetic control.

Third, the results of the present study have limited generalizability. This was only an observational study based on the data from a single institution. In addition, our "visiting diabetes patients" included only very compliant patients who had survived 13 years of diabetes, which introduced bias in the results. Therefore, at best, the results are limited in their applicability to extremely compliant patients with diabetes in Japan.

\section{Conclusions}

The present study revealed a tendency toward longterm improvements in indicators of diabetic control and revealed that there were major changes in the prescribing frequencies of the most common antidiabetic medications at our institution. However, these changes were consistent with changes in guideline recommendations over the study period. We conclude that new antidiabetic medications and treatment strategies might have positive effects on diabetes management but that further multicenter research is needed.

\section{Additional files}

Additional file 1: Table S1. The glycated hemoglobin and glycated albumin data in the first repeated cross-sectional study.

Additional file 2: Table S2. The antidiabetic medication prescription data obtained in the second repeated cross-sectional study.

Additional file 3: Table S3. The glycated hemoglobin and glycated albumin data obtained in the retrospective cohort study.

Additional file 4: Table S4. Antidiabetic medication prescription data obtained in the retrospective cohort study.

\begin{abstract}
Abbreviations
HbA1c: glycated hemoglobin; ID: identification; JDS: Japan Diabetes Society; IFCC: International Federation of Clinical Chemistry; NGSP: national glycohemoglobin standardization program; ICD: international statistical classification of diseases and related health problems; JDDM: The Japan Diabetes Clinical Data Management Study Group.
\end{abstract}

\section{Authors' contributions}

KF designed and conducted the analysis, interpreted the data, and wrote the manuscript. MH designed the analysis, led the data collection, and reviewed and edited the manuscript. HY contributed to data analysis and interpretation, drafting of the manuscript, and critical reviewing and editing of the manuscript. TN contributed to the study design and critical reviewing and editing of the manuscript. All authors read and approved the final manuscript.

\section{Author details}

1 Department of General Medicine, School of Medicine, Juntendo University, 3-1-1, Hongo, Bunkyo-ku, Tokyo 113-8421, Japan. ${ }^{2}$ Endocrinology and Metabolism Division, NTT Medical Center Tokyo, 5-9-22 Higashi-Gotanda, Shinagawa-ku, Tokyo 141-8625, Japan.

\section{Acknowledgements}

We would like to express our thanks to the Healthcare Information Technologist Mr Kouhei Hayashi at the NTT Kanto Medical Center Tokyo whose work made an enormous contribution to our study. The authors would like to thank Enago (www.enago.jp) for the English language review.

\section{Competing interests}

Kazutoshi Fujibayashi is an employee of NTT Kanto Medical Center, Tokyo; Michio Hayashi received an honorarium from Takeda Pharmaceutical Company Limited.

\section{Availability of data and materials}

The ethics committee imposed restrictions to data access and sharing. Individuals who wish to access our data must obtain further permission from the committee, which can be achieved by contacting the corresponding author.

\section{Ethics approval and consent to participate}

The study protocol was approved by the institutional ethics committee of NTT Medical Center, Tokyo (No.14-256). All examinations were performed during routine clinical practice, and none were specifically performed to collect data for this study, so written informed consent was not necessary from patients.

\section{Funding}

This study was funded by the Center for Clinical Epidemiology at St Luke's International University and a 2016 Grant-in-Aid for Scientific Research (C) (No. 16K09041).

Received: 2 September 2016 Accepted: 4 November 2016

Published online: 10 November 2016 


\section{References}

1. Guariguata L, Whiting DR, Hambleton I, Beagley J, Linnenkamp U, Shaw JE. Global estimates of diabetes prevalence for 2013 and projections for 2035. Diabetes Res Clin Pract. 2014;103:137-49.

2. Ministry of Health, Labour and Welfare. The National Health and Nutrition Survey in Japan. 2013. http://www.mhlw.go.jp/bunya/kenkou/eiyou/dl/ h25-houkoku.pdf. Accessed 1 Jan 2016. (in Japanese).

3. International Diabetes Federation. IDF Diabetes Atlas. 6th ed. Belgium: Int Diabetes Federat; 2013. p. 9-17.

4. Ng JM, Cooke M, Bhandari S, Atkin SL, Kilpatrick ES. The effect of iron and erythropoietin treatment on the $\mathrm{A} 1 \mathrm{C}$ of patients with diabetes and chronic kidney disease. Diabetes Care. 2010;33:2310-3.

5. Dubowitz N, Xue W, Long Q, Ownby JG, Olson DE, Barb D, et al. Aging is associated with increased $\mathrm{HbA} 1 \mathrm{c}$ levels, independently of glucose levels and insulin resistance, and also with decreased $\mathrm{HbA} 1 \mathrm{c}$ diagnostic specificity. Diabets Med. 2014;31:927-35.

6. Hashimoto K, Koga M. Indicators of glycemic control in patients with gestational diabetes mellitus and pregnant women with diabetes mellitus. World J Diabetes. 2015;6:1045-56

7. Koga M, Kasayama S. Clinical impact of glycated albumin as another glycemic control marker. Endocr J. 2010;57:751-62.

8. Freedman BI, Andries L, Shihabi ZK, Rocco MV, Byers JR, Cardona CY, et al. Glycated albumin and risk of death and hospitalizations in diabetic dialysis patients. Clin J Am Soc Nephrol. 2011;6:1635-41.

9. PeacockTP, Shihabi ZK, Bleyer AJ, Dolbare EL, Byers JR, Knovich MA, et al. Comparison of glycated albumin and hemoglobin A(1c) levels in diabetic subjects on hemodialysis. Kidney Int. 2008;73:1062-8.

10. American Diabetes Association. Standards of medical care for patients with diabetes mellitus. Diabetes Care. 2002;25:213-29.

11. Matsuzawa Y. Metabolic syndrome-definition and diagnostic criteria in Japan. J Atheroscler Thromb. 2005;12:301.

12. Nathan DM, Buse JB, Davidson MB, Heine RJ, Holman RR, Sherwin R, Zin man B. Management of hyperglycemia in type 2 diabetes: a consensus algorithm for the initiation and adjustment of therapy: a consensus statement from the American Diabetes Association and the European Association for the Study of Diabetes. Diabetes Care. 2006;29:1963-72.

13. International Diabetes Federation. Guideline for management of postmeal glucose. 2007. https://www.idf.org/webdata/docs/Guideline_PMG_ final.pdf\#search=\%27IDF+postprandial+hyperglycemia+2007\%27. Accessed 8 Oct 2016

14. Inzucchi SE, Bergenstal RM, Buse JB, Diamant M, Ferrannini E, Nauck M, et al. American Diabetes Association (ADA); European Association for the Study of Diabetes (EASD). Management of hyperglycemia in type 2 diabetes: a patient-centered approach: position statement of the American Diabetes Association (ADA) and the European Association for the Study of Diabetes (EASD). Diabetes Care. 2012:35:1364-79.

15. Committee on the Standardization of Diabetes Mellitus-Related Laboratory Testing of Japan Diabetes Society. International clinical harmonization of glycated hemoglobin in Japan: from Japan Diabetes Society to National Glycohemoglobin Standardization Program values. J Diabetes Invest. 2012:3·39-40.
16. International Federation of Clinical Chemistry (IFCC) Standardization of HbA1c. Available at: http://www.ngsp.org/docs/IFCCstd.pdf. Accessed 12 April 2016.

17. International Statistical Classification of Diseases and Related Health Problems: ICD -10 Version: 2016. http://apps.who.int/classifications/icd10/ browse/2016/en. Accessed 10 May 102016.

18. Japanese Diabetes Society. Treatment Guide for Diabetes 2014-2015. BUNKODO: Japan; 2014 (in Japanese).

19. The Japan Diabetes Clinical Data Management Study Group. Basic statistical data Figure 3: Mean HbA1c in each year. (2013). http://jddm.jp/data/ index-2013.html. Accessed 30 Jan 2016. (in Japanese)

20. UK Prospective Diabetes Study. UKPDS) Group. Intensive blood-glucose control with sulphonylureas or insulin compared with conventional treatment and risk of complications in patients with type 2 diabetes (UKPDS 33. Lancet. 1998;352:837-53.

21. The Diabetes Control and Complications Trial Research Group. The effect of intensive treatment of diabetes on the development and progression of long-term complications in insulin-dependent diabetes mellitus. N Engl J Med. 1993;329:977-86.

22. Ohkubo Y, Kishikawa H, Araki E, Miyata T, Isami S, Motoyoshi S, et al. Intensive insulin therapy prevents the progression of diabetic microvascular complications in Japanese patients with non-insulin-dependent diabetes mellitus: a randomized prospective 6-year study. Diabetes Res Clin Pract. 1995:28:103-17.

23. UK Prospective Diabetes Study. UKPDS) Group. Effect of intensive bloodglucose control with metformin on complications in overweight patients with type 2 diabetes (UKPDS 34. Lancet. 1998;352:854-65.

24. Goto A, Arah OA, Goto M, Terauchi Y, Noda M. Severe hypoglycaemia and cardiovascular disease: systematic review and meta-analysis with bias analysis. BMJ. 2013;347:f4533.

25. Zoungas S, Patel A, Chalmers J, de Galan BE, Li Q, Billot L, et al. Severe hypoglycemia and risks of vascular events and death. N Engl J Med. 2010;363:1410-8.

26. McCoy RG, Van Houten HK, Ziegenfuss JY, Shah ND, Wermers RA, Smith SA. Increased mortality of patients with diabetes reporting severe hypoglycemia. Diabetes Care. 2012;35:1897-901.

27. American Diabetes Association. (7) Approaches to glycemic treatment Diabetes Care. 2015:38:541-8.

28. Hampp C, Borders-Hemphill V, Moeny DG, Wysowski DK. Use of antidiabetic drugs in the U.S., 2003-2012. Diabetes Care. 2014;37:1367-74.

29. Lewis JD, Ferrara A, Peng T, Hedderson M, Bilker WB, Quesenberry CP $\mathrm{Jr}$, et al. Risk of bladder cancer among diabetic patients treated with pioglitazone: interim report of a longitudinal cohort study. Diabetes Care. 2011;34:916-22.

30. Grey A. Thiazolidinedione-induced skeletal fragility-mechanisms and implications. Diabetes Obes Metab. 2009;11:275-84.

\section{Submit your next manuscript to BioMed Central and we will help you at every step:}

- We accept pre-submission inquiries

- Our selector tool helps you to find the most relevant journal

- We provide round the clock customer support

- Convenient online submission

- Thorough peer review

- Inclusion in PubMed and all major indexing services

- Maximum visibility for your research

Submit your manuscript at www.biomedcentral com/submit
C BioMed Central 